\title{
INSIGHTS
}

\section{Family reflections on HIE}

\author{
Nick Burton ${ }^{1}$ \\ Pediatric Research (2019) 85:11-12; https://doi.org/10.1038/s41390-018-0168-8
}

Our first son, Grey, was born in 2015 in a not-breathing condition. He was blue and floppy, and after the first thirty seconds or so I knew his brain was at risk. My wife had a completely uneventful pregnancy, which included an ultrasound 3 days before his birth that showed Grey rolling around and sucking his thumb. The first sign we were given of something amiss was his appearance the first time we saw him. It took almost 10 min and three epinephrine shots before his heart started. He needed to be intubated, and required a chest tube due to a collapsed lung. We were introduced to the idea of brain cooling, a treatment that we would have to be transferred for. We were moved to a higher-level neonatal intensive care unit (NICU), where they could begin the cooling process.

Grey was kept in the NICU for a month, then shifted to a rehab hospital next door for another 2 months. He was unconscious for his first ten days, at which point he received magnetic resonance imaging, which showed global brain damage. Over that admission, he needed lesser and lesser breathing support, but ended up having a trach placed due to a vocal cord paresis. He was given a g-tube as well. As parents, we were shown how to care for his special needs, and went through the process of setting up athome nursing. We were told that he would never be able to walk, talk, or eat by mouth.

There is really no way to overstate how hypoxic-ischemic encephalopathy (HIE) has affected Grey's life. He is now three, and, with spastic quad cerebral palsy, is still mostly non-mobile and non-verbal. He has seizures that are occasionally under control by way of the four sedating medications he's on. His vocal cord paresis has resolved, but he still requires his trach due to his copious secretions that we suction, sometimes as often as every $5 \mathrm{~min}$. He underwent a salivary gland removal/abatement surgery that offered fractional help for this. He has been hospitalized no less than ten times for any of pneumonia, respiratory syncytial virus, flu, or to be viewed on video encephalotgrams for his seizures. He receives Early Intervention therapy for physical therapy, occupational therapy, and developmental interventions, and we see an outpatient feeding/vision therapist. As his dad, I had to leave my career to stay home with him and manage his therapies and specialist visits.

Looking at potential research, it's hard to point to just one thing that would benefit children given an HIE diagnosis. An HIE injury can range so much in severity, and the outcomes can range from unaffected to quite severely affected. Some parents are worried about motor-planning and late potty training, while others are worried about whether their child will ever smile or use their body. Some are worried about behavioral issues, while others are trying to wean their kid off a vent. Some are wondering if their child will ever present any symptoms, while others are worried about life expectancy. That's why research in prevention and initial treatment would affect all possible cases.

One thing that seems to be common among many HIE parents is that there was no forewarning for this injury. They were told all through their pregnancy and labor that "everything was fine." Whether a hypoxic event was due to a knot in the cord, uterine rupture, or some kind of aspiration, there must be better ways to identify these issues earlier and help prevent a catastrophic event. Research into the many causes of HIE in an attempt to find clearer warning signs, better monitoring techniques, and sharper best doctor practices could be a huge breakthrough in helping to prevent HIE cases. In our case, we were never even aware that HIE was a potential hazard of delivery. When the doctor mentioned that there was meconium present during labor, we were told that it was normal and nothing to be concerned about. Our son aspirated on meconium, and it would have changed his life if the doctor had recommended a c-section once it was detected. We were never really aware of the risks of our situation. Finding new data on HIE rates, causes, and treatments during labor could also help educate expectant parents and the health professionals who treat them. While considering neonatal $\mathrm{HIE}$, as well as children who suffered HIE during a near-SIDS (sudden infant death syndrome) event, cardiac arrest, or other manner during childhood, we believe that analyzing the most common causes and trying to decrease them is the best way to begin. Any decrease of the instances of HIE would be a victory.

Aside from prevention, it would be nice to see research into consistent initial treatments that might prevent a worsening of the injury. While our son was able to receive brain cooling, it is still not standard at all hospitals, and there is inconsistency in where/why full-body cooling is offered. Research into these treatments, and any similar methods of quelling the initial insult could help build a case for more hospitals to employ them. It's great to see that cooling has become standard practice, but there may be more that can be done during those first critical hours and studies are being done worldwide on additional treatment options. While maybe not deserving of as much time and resources as prevention or later-life treatment, researching how to keep HIE as just an injury and not a life-altering diagnosis could be fruitful.

Research into treatments that somehow improve brain function would also be important for our families. When looking into what's currently available, there are very limited options. There are stem cell treatments available, which are not FDA approved, and prohibitively expensive. The notion of flying to Panama and paying $\$ 20,000$ for an injection of stem cells, which has no peerreviewed research attesting to its effectiveness, is daunting. There are "plasticity centers," which claim to improve brain function using various exercises and unique therapeutic machinery, but they are also priced way outside of what insurance would cover.

${ }^{1}$ Vice President of Outreach, Hope for HIE Foundation, Freehold, NJ, USA
Correspondence: Nick Burton (info@pedres.org)

Received: 14 August 2018 Accepted: 24 August 2018

Published online: 22 October 2018 
They, too, have questions about effectiveness and are limited in which outcomes they can treat. There are other therapies, like the Anat Baniel method and Feldenkrais, which exist as alternative treatments with only anecdotal evidence to support them. Any research that would either help support these treatments or help disqualify their usefulness would be meaningful. There also seems to be an overlap into treatments aimed at stroke patients, and finding ways to employ those techniques here might also make sense.

I, and our group of almost 4000 parents, greatly appreciate that you've decided to undertake research into $\mathrm{HIE}$, and that you're interested in our point of view. Our families have gone through a similar experience. For those whose kids experienced a birth injury, we share the feeling of anticipating one of the best moments of our lives, only to end up facing one of the worst. With
Grey on the severe end, our family has seen too many health professionals that look at us helplessly-like there's nothing to be done for our son. While we've learned to align our family with doctors who look at our son with optimism, we know that there's only so much they can do. There is one sentiment that we were told in the NICU, and that I've heard other parents express: A doctor told us "medicine has figured out how to resuscitate really well, but hasn't really figured out what to do next." Please help change that, or even better, the need for resuscitation in the first place.

Nick Burton

VP Outreach

Hope for HIE Foundation 